\title{
Progression of alcoholic acute to chronic pancreatitis
}

\author{
R W Ammann, B Muellhaupt
}

\begin{abstract}
Alcoholic chronic pancreatitis usually progresses from acute attacks to chronic pancreatitis within one to 19 years. The factors responsible for the appreciable variability in progression are unclear. In this study the relation between progression and the incidence and severity of acute episodes in a large cohort of patients with alcoholic chronic pancreatitis was analysed. All patients with at least one documented episode of acute pancreatitis have been studied prospectively over the past 30 years according to our protocol. Patients were classified according to their long term course into (a) calcific $(n=185)$, (b) non-calcific $(n=30)$, and (c) non-progressive $(n=39)$ chronic pancreatitis groups. The yearly incidence of acute attacks of pancreatitis was significantly higher in groups (a) and (b) than in group (c). Furthermore, the progression rate to advanced chronic pancreatitis (groups (a) and (b)) correlated with the incidence of severe pancreatitis (associated with pseudocysts in more than 55\%). Pseudocysts were located primarily in the cephalic pancreas in groups (a) and (b) (58-71\%) and in the pancreatic tail in group (c) $(61 \%)$. In conclusion, these data suggest that the progression of acute to chronic pancreatitis is closely related to the incidence and severity of acute attacks. This finding and the primary location of pseudocysts in the cephalic pancreas (groups (a) plus (b)) are compatible with the 'necrosis-fibrosis' pathogenetic hypothesis.

(Gut 1994; 35: 552-556)
\end{abstract}

The relationship between acute and chronic pancreatitis has long been debated. In 1946, Comfort $e$ al suggested that chronic pancreatitis was the consequence of repeated attacks of acute pancreatitis.' This hypothesis was based on a long term study of 29 patients with recurrent alcoholic (or non-biliary) pancreatitis. In the early $60 \mathrm{~s}$, Sarles et al postulated that chronic pancreatitis could hardly be the consequence of acute pancreatitis since patients with this disorder were a mean of 13 years older when they had their first attack and more women than men are affected. ${ }^{2}$ Sarles's series of acute pancreatitis, however, was based primarily on patients with biliary (or non-alcoholic) pancreatitis. ${ }^{2}$ Since the classic published reports of Howard and Ehrlich ${ }^{34}$ and Marks et al, ${ }^{5}$ the differences in the natural histories of biliary and alcoholic pancreatitis have been generally recognised. Nevertheless, in the definitions of Marseille meetings (in 1963 and 1984), the aetiology was not considered an important factor in terms of the outcome of pancreatitis. ${ }^{6}$ Thus, for the past 30 years acute and chronic pancreatitis have been separated into two distinct entities irrespective of aetiology. ${ }^{7}$ Much confusion has resulted from the authoritative statement of the two Marseille meetings that progression of acute to chronic pancreatitis is extremely uncommon. ${ }^{6}$

Alcohol abuse is the most common cause of chronic pancreatitis in western countries. The natural history of alcoholic chronic pancreatitis is characterised by recurrent episodes of pancreatitis in the early stages and by progressive pancreatic dysfunction, often associated with calcification, in the late stages. ${ }^{158}$ Some experts assume that alcoholic 'acute' pancreatitis occurs regularly on the basis of pre-existent, clinically latent chronic pancreatitis. ${ }^{9-11}$ This hypothesis has been challenged recently by a prospective long term study which indicated that about $30 \%$ of patients with recurrent alcoholic pancreatitis did not progress to advanced chronic disease. ${ }^{12}$

The pathogenesis of chronic pancreatitis is still obscure. There have been various suggestions, most notably the 'toxic-metabolic' and the 'protein-plug' hypotheses. ${ }^{13}$ Klöppel and Maillet recently made a further proposition, based on histopathology, that chronic pancreatitis may develop as a late sequelum of necrotising pancreatitis $^{14}$ (Fig 1). We tested this 'necrosisfibrosis' hypothesis using data from our prospective long term study of alcoholic chronic pancreatitis. ${ }^{812}$ In particular, the incidence and severity of acute attacks of alcoholic pancreatitis were analysed, based on the hospital records in well defined cohorts of patients with calcific, non-calcific, and non-progressive chronic pancreatitis. ${ }^{812}$

DEFINITIONS

The duration of disease is the time between onset (first typical episode of pancreatitis) and either the cut off point (June 1992), the last personal contact, or the death of the patient. The course of the disease up to the first personal contact (equal to entry) was analysed, based on hospital records. The patients were studied prospectively at regular intervals from entry until the last contact (equal to follow up time) according to our protocol. ${ }^{8}$ Alcohol was considered a cause in patients who had consumed $\geqslant 80 \mathrm{~g}$ pure ethanol daily for at least five years.

The diagnosis of advanced chronic pancreatitis was based upon a typical history and on one or more of the following:

(1) Pancreatic calcification seen on $x$ ray $^{8}$;

(2) Typical pancreatic histology, ${ }^{2}$ associated with persistent exocrine insufficiency (faecal chymotrypsin $<120 \mu \mathrm{g} / \mathrm{g}$ for at least two years $)^{8}$;

(3) Persistent exocrine insufficiency or pancreatic steatorrhea, or both $(>7 \mathrm{~g} / 24 \mathrm{~h}$; chymotrypsin $<7.5 \mathrm{mg} / 24 \mathrm{~h}$ ).

A diagnosis of non-progressive chronic pan-

creatitis was based on a typical history of
Service, Department Hospital, CH-8091 Zurich, Switzerland R W Ammann Correspondence to: Professor R W Ammann Accepted for publication 9 August 1993 

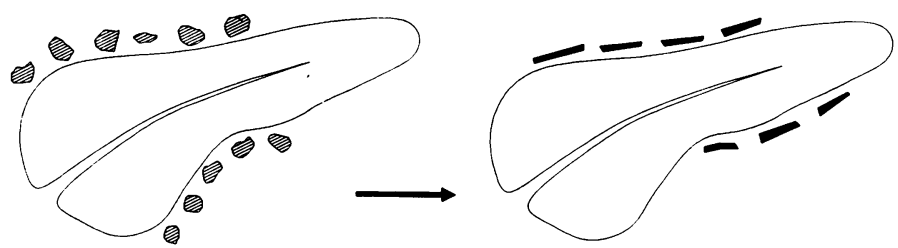

Biliary pancreatitis

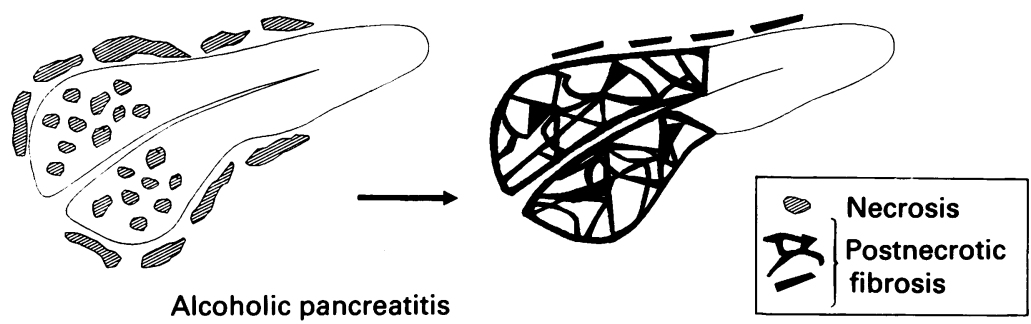

Figure 1: Scheme of the 'necrosis-fibrosis' hypothesis of chronic pancreatitis. ${ }^{14}$ Note: severe alcoholic pancreatitis is associated with (fatty) necrosis within the pancreas (in contrast to biliary pancreatitis). Postnecrotic fibrosis may distort the duct outflow tract and thereby an upstream spread of inflammation and acinar destruction will result.

(recurrent) alcoholic pancreatitis but without progression to advanced chronic pancreatitis despite a duration of disease of more than six years ( ${ }^{12}$ (unpublished data). In non-progressive chronic pancreatitis the typical markers of advanced disease, in particular, pancreatic dysfunction, calcification, and pancreatic duct dilation, were absent. Histological findings in some of the patients with adequate documentation showed unequivocal chronic pancreatitis.

\section{Patients and methods}

Between July 1963 and June 1992, 254 patients with at least one documented episode of alcoholic acute pancreatitis were studied prospectively according to a protocol previously outlined. ${ }^{8}$ Twenty five additional patients of this series with primarily painless alcoholic chronic pancreatitis were excluded $(10 \%)$. The yearly control studies at our gastroenterology unit included:

(1) A clinical evaluation of weight, pain, diarrhoea, alcohol intake, hospitalisation, and medication;

(2) A physical examination;

(3) Routine laboratory tests;

(4) Pancreatic function tests, particularly serum pancreatic enzymes, faecal chymotrypsin; ${ }^{8}$

(5) Postprandial blood glucose concentrations or glucose tolerance test;

(6) Plain $x$ ray films of the pancreatic area in three projections.

Additional studies, for example, ultrasonography, computed tomography (CT), endoscopic retrograde cholangiopancreatography (ERCP), and faecal fat studies were carried out when indicated. Alcohol intake was documented by repeated questioning of the patient and family members, and with the help of social workers. All other known causes of pancreatitis were excluded by appropriate studies in patients classified as having alcoholic pancreatitis.

Based on the long term course, the 254 patients were classified into three categories, namely:
(1) Calcific chronic pancreatitis $(n=185)$ (CCP);

(2) Non-calcific chronic pancreatitis $(n=30)$ (NCP);

(3) Non-progressive chronic pancreatitis ( $n=$ 39) (NPCP).

Seven additional patients in the last group were excluded because of a duration of disease of six or fewer years.

All hospital, surgical, histopathological, and autopsy records of each patient were reviewed retrospectively to assess the incidence and severity of acute pancreatitis and its complications. The diagnosis of acute pancreatitis was based on a consistent clinical picture associated with an appreciable documented increase in pancreatic serum enzyme activities (three or more times the upper limit). Pain episodes without laboratory confirmation were only considered as acute attacks in patients with typical clinical findings, one to several documented previous episodes of pancreatitis, and without an extrapancreatic cause of epigastric pain. The severity of attacks was graded into mild or severe. There are no generally accepted criteria to define severe attacks, ${ }^{15}$ and different classifications have been described. For the present study attacks of pancreatitis were considered severe if one or more of the following criteria were fulfilled:

(1) Local complications existed, such as pseudocysts, abscesses;

(2) Systemic complications, for example, shock, pulmonary complications with hypoxaemia or radiological signs, or both, renal failure;

(3) Metabolic disturbance such as transient hyperglycaemia/glycosuria or marked hypocalcaemia existed;

(4) Patients were in hospital for $>15$ days.

The proportion of severe attacks in the present series was about $30 \%$, which is comparable with the current published reports. ${ }^{16}$ Severe attacks were associated with pseudocysts (or abscesses) in $55.6 \%$ of patients. The diagnosis of pseudocysts or abscesses was established primarily by ultrasound, CT, or ERCP and was confirmed by surgery. The pseudocysts occurred primarily within the first six years from onset $(>85 \%)$ in association with acute pancreatitis (that is, most were probably post-necrotic cysts).

The rate of attacks of pancreatitis in the three subgroups was calculated on a yearly basis. The incidence of attacks was considered in the NPCP group for the whole duration of disease, in the CCP and the NCP groups, however, only the time from onset to the diagnosis of chronic pancreatitis was included.

The statistical analysis for these unpaired non-parametric data was performed with the Kruskal-Wallis (three groups or more) or the Mann-Whitney U test (two groups). For all studies, a $p$ value $<0.05$ was considered statistically significant. The values of all variables are expressed as mean (SD).

\section{Results}

The relevant clinical data for the 254 patients are summarised in Table I. CCP was the largest 
TABLE I Relevant clinical data in patients with chronic pancreatitis $(C P)$

\begin{tabular}{|c|c|c|c|c|}
\hline & $\begin{array}{l}\text { Calcific } C P \\
(C C P)\end{array}$ & $\begin{array}{l}\text { Non-calcific } C P \\
(N C P)\end{array}$ & $\begin{array}{l}\text { Non-progressive } \\
C P(N P C P)\end{array}$ & p Value \\
\hline $\begin{array}{l}\text { No of patients } \\
\text { Male/female ratio } \\
\text { Age at onset (y): }\end{array}$ & $\begin{array}{l}185 \\
8 \cdot 7\end{array}$ & $\begin{array}{l}30 \\
9 \cdot 0\end{array}$ & $\begin{array}{l}39 \\
12 \cdot 0\end{array}$ & NS \\
\hline $\begin{array}{l}\text { Mean (SD) } \\
\text { Range }\end{array}$ & $\begin{array}{l}38 \cdot 37(10 \cdot 05) \\
20-70\end{array}$ & $\begin{array}{l}40 \cdot 33(9 \cdot 97) \\
22-63\end{array}$ & $\begin{array}{l}38 \cdot 69(7 \cdot 5) \\
25-55\end{array}$ & NS \\
\hline $\begin{array}{l}\text { Follow up (y): } \\
\text { Mean (SD) } \\
\text { Range }\end{array}$ & $\begin{array}{l}10 \cdot 28(5 \cdot 8) \\
0-20\end{array}$ & $\begin{array}{l}8 \cdot 37(5 \cdot 46) \\
2-25\end{array}$ & $\begin{array}{l}10 \cdot 13(5 \cdot 2) \\
2-23\end{array}$ & NS \\
\hline $\begin{array}{l}\text { Duration of disease }(\mathrm{y}) \text { : } \\
\text { Mean (SD) } \\
\text { Range }\end{array}$ & $\begin{array}{l}13 \cdot 37(6 \cdot 18) \\
2-23\end{array}$ & $\begin{array}{l}10 \cdot 3(5 \cdot 85) \\
2-25\end{array}$ & $\underset{6-23}{11 \cdot 13(5 \cdot 16)}$ & $\begin{array}{l}\text { CCP/NCP }<0.01 \\
\text { CCP/NPCP }<0.05 \\
\text { NCP/NPCP NS }\end{array}$ \\
\hline
\end{tabular}

group by far, while the NCP and NPCP groups were comparable in size. In all three groups, the sex and age distributions were about equal (Table I). The time of follow up was similar in the three groups, but the duration of disease was significantly longer in the CCP group than in the other two (Table I). The diagnosis of chronic pancreatitis was established $4 \cdot 8(3 \cdot 8)$ years from onset in the CCP group and $5 \cdot 4(4 \cdot 8)$ years from onset in the NCP group (NS).

The incidence of acute attacks of pancreatitis (mild and severe) was significantly higher in the CCP than in the NCP and NPCP groups (Table II). No significant difference was noted between the NCP and NPCP groups (Table II). The incidences of severe attacks were similar in the CCP and NCP groups but significantly lower in the NPCP group (Table II).

The incidence of pseudocysts did not differ significantly between the three subgroups, even though it was almost double in the CCP and NCP groups compared with the NPCP group (Table III). Interestingly, the pseudocysts occurred primarily in the cephalic pancreas in the CCP (71\%) and the NCP groups (58\%), but in the NPCP group $61 \%$ originated in the pancreatic tail (Table III).

The progression rate in advanced chronic pancreatitis was closely related to the incidence of severe attacks of pancreatitis, that is the shorter the time between the onset and diagnosis of chronic pancreatitis the greater the incidence of severe pancreatitis (Fig 2).

\section{Discussion}

The results of the present study suggest that progression (or non-progression) of alcoholic pancreatitis to advanced chronic disease is determined primarily by two factors - the incidence and severity of acute attacks of pancreatitis and the localisation of necrosis (that is, pseudocysts) within the cephalic portion of the pan-

TABLE II Incidence of acute attacks of pancreatitis in the three groups of patients with chronic pancreatitis $(C P)$

\begin{tabular}{lllll}
\hline Acute attacks/y & $\begin{array}{l}\text { Calcific CP } \\
(C C P)\end{array}$ & $\begin{array}{l}\text { Non-calcific } \\
C P(N C P)\end{array}$ & $\begin{array}{l}\text { Non-progressive } \\
C P(N P C P)\end{array}$ & $p$ Value \\
\hline $\begin{array}{l}\text { Total no (mild/severe): } \\
\text { Mean (SD) }\end{array}$ & $1 \cdot 37(1 \cdot 17)$ & $1 \cdot 02(1 \cdot 32)$ & $0.26(0.19)$ & $\begin{array}{l}\text { CCP/NCP }<0.05 \\
\text { CCP/NPCP }<0.001\end{array}$ \\
$\begin{array}{l}\text { Range } \\
\begin{array}{l}\text { Severe attacks/y: } \\
\text { Mean (SD) }\end{array}\end{array}$ & $0.06-6.0$ & $0.04-7.0$ & $0.06-1.0$ & NCP/NPCP NS \\
Range & $0.44(0.54)$ & $0.43(0.39)$ & $0.11(0.13)$ & $\begin{array}{l}\text { CCP/NCP NS } \\
\text { CCP/NPCP }<0.001\end{array}$ \\
\hline
\end{tabular}

creas. These data are at variance with the current view that virtually no transition exists between acute and chronic pancreatitis. ${ }^{6}$

\section{SHORT TERM STUDIES AFTER ACUTE (ALCOHOLIC)} PANCREATITIS

Increasing evidence for a transition from acute to chronic pancreatitis has been presented in recent years. In several prospective short term studies, functional impairment or persistent morphological changes (on ERCP), or both, have been noted after acute pancreatitis in man. ${ }^{17-21}$ Full recovery of exocrine function may not occur within four years of onset, depending on the severity of the acute pancreatitis. ${ }^{20}$ Similar results were reported for the recovery of endocrine function..$^{202}$ On ERCP, moderate or severe ductal changes compatible with chronic pancreatitis after necrohaemorrhagic pancreatitis were noted in about $50 \%$ of patients in one study, but no progression of these changes occurred during the four years of follow up. ${ }^{19}$ In some series, the functional and morphological changes were more pronounced after alcoholic than biliary pancreatitis. ${ }^{20}$ Whether or not these changes in function and morphology were the first evidence of progression to chronic pancreatitis cannot be resolved because of the short follow up (four or fewer years). ${ }^{19-21}$ However, these data suggest a broad overlap between acute and chronic pancreatitis, particularly in the early phase after alcoholic pancreatitis.

LONG TERM STUDIES: ALCOHOLIC CHRONIC PANCREATITIS IN RELATION TO INCIDENCE, SEVERITY OF ACUTE PANCREATITIS, AND PSEUDOCYSTS

There are only few prospective clinical long term studies of alcoholic acute pancreatitis (five years or longer) and the data are controversial. According to Gullo et al, alcoholic pancreatitis regularly progresses to advanced chronic pancreatitis, ${ }^{9}$ but progression may be delayed in patients who have stopped abusing alcohol. ${ }^{22}$ In accordance with these results, most patients with alcoholic pancreatitis in the present series progressed to advanced chronic disease (Table I). A subgroup of patients, however, did not develop the hallmarks of advanced disease irrespective of alcohol intake (NPCP). This subgroup may be identical with 'small-duct' chronic pancreatitis, an ill defined entity mentioned mainly in surgical

TABLE III Incidence and location of pseudocysts in the three groups of patients with chronic pancreatitis $(C P)$

\begin{tabular}{|c|c|c|c|}
\hline Incidence & $\begin{array}{l}\text { Calcific } C P \\
(C C P)\end{array}$ & $\begin{array}{l}\text { Non-calcific } \\
C P(N C P)\end{array}$ & $\begin{array}{l}\text { Non-progressive } \\
C P(N P C P)\end{array}$ \\
\hline \multicolumn{4}{|l|}{ Total no/y: } \\
\hline Mean (SD) & $0 \cdot 13(0 \cdot 24)$ & $0 \cdot 11(0 \cdot 16)$ & $0.06(0.09)$ \\
\hline Range & $0-1 \cdot 0$ & $0-0.5$ & $0-0.38$ \\
\hline \multicolumn{4}{|c|}{ Location of pseudocysts (no (\%)): } \\
\hline Head/body & $49(71)$ & $7(58)$ & $5(28)$ \\
\hline Tail & $16(23)$ & $3(25)$ & $10(61)$ \\
\hline Unknown or & & & \\
\hline Total no & $68(100)$ & $12(100)$ & $17(100)$ \\
\hline
\end{tabular}

In the CCP and NCP groups only pseudocysts which occurred before the diagnosis of $\mathrm{CP}$ are considered. Infected pseudocysts and postnecrotic abscesses are included in these figures. 
Figure 2: The progression rate (interval between onset and diagnosis of advanced chronic pancreatitis) is closely related with the incidence of severe attacks of pancreatitis in calcific and non-calcific chronic pancreatitis (CCP and $N C P$ ).

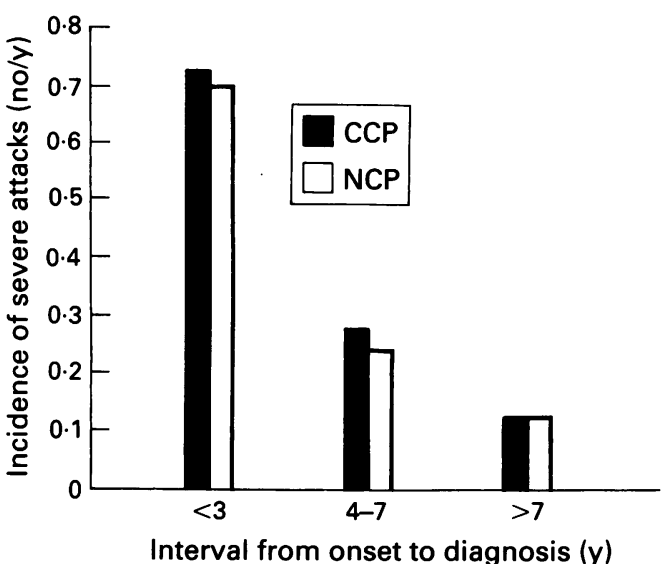

published reports, which does not progress to advanced ('large-duct') chronic pancreatitis. ${ }^{23}$

These data suggest that the progression (or non-progression) of alcoholic pancreatitis to advanced chronic pancreatitis is correlated with the total incidence of acute attacks of pancreatitis (mild and severe) (Table II). In addition, a significant difference in the incidence of severe acute pancreatitis and the final outcome was found between the CCP or NCP groups and the NPCP group (Table II). Furthermore, the rate of progression to CCP and NCP correlated with the incidence of severe attacks of pancreatitis (Fig 2). It may be argued that the severity grading of acute attacks on the basis of a retrospective review of hospital records was rather imprecise. It is obvious that the available clinical, morphological, and biological data did not permit the application of a sophisticated score index as designated by some experts. ${ }^{15}$ However, the grading system was probably appropriate, which is supported by the fact that over $55 \%$ of patients with severe acute pancreatitis developed (probably postnecrotic) pseudocysts or abscesses.

The incidence of pseudocysts in the three groups was not significantly different (Table III). It should be noted, however, that the pseudocysts were primarily located in the cephalic pancreas in the CCP and NCP groups and in the pancreatic tail in the NPCP group (Table III). This is in accordance with the results of some large series of patients with alcoholic chronic pancreatitis in whom pseudocysts were found more often in the head or body $(75-88 \%)$ than in the tail of the pancreas $(10-14 \%) .{ }^{24-28}$

It is possible that in patients with cephalic pseudocysts, postnecrotic fibrosis induces obstruction of the pancreatic ducts which causes progressive upstream acinar destruction and fibrosis as suggested in the 'necrosis-fibrosis' hypothesis $^{14}$ (Fig 1). This assumption is supported by recent animal studies of bile saltinduced acute pancreatitis in rats. ${ }^{29}$ In these experiments persistent chronic pancreatic lesions were observed focally in those lobules which were drained by large pancreatic ducts obstructed by fibrosis. ${ }^{29}$ Such a mechanism may also be implicated in some patients with postnecrotic, non-alcoholic chronic pancreatitis. ${ }^{30}$

It seems less likely that the 'necrosis-fibrosis' hypothesis is also applicable to primary painless chronic pancreatitis because extensive necrosis associated with acute pancreatitis does not usually occur without severe clinical symptoms such as abdominal pain, shock, or multi-organ failure. Therefore, $10 \%$ of patients with painless alcoholic chronic pancreatitis were excluded from this series (see Methods). According to some experts, alcoholic acute pancreatitis is regularly superimposed on clinically latent chronic pancreatitis. ${ }^{1011}$ Since no histology at onset of 'acute' pancreatitis is available in the present series, this thesis cannot be disproved. However, in a recent autopsy series of 247 patients with fatal acute alcoholic pancreatitis, $53 \%$ of cases had histologically acute pancreatitis unassociated with chronic changes. ${ }^{31}$

Accordingly, these data challenge the Marseille classification which negates the transition from acute to chronic pancreatitis. This seems to be true for gall stone pancreatitis, but is obviously unlikely for alcoholic pancreatitis.

Additional prospective long term studies in large series of patients with acute pancreatitis with well defined severity are necessary to confirm (or refute) our findings. Future research regarding the pathophysiology of chronic pancreatitis should take into account the facts that there are probably:

(1) Different subgroups of chronic pancreatitis (for example, alcoholic $v$ non-alcoholic chronic pancreatitis; progressive $v$ nonprogressive chronic pancreatitis; and chronic pancreatitis with recurrent attacks of pancreatitis $v$ primary painless chronic pancreatitis);

(2) Probably more than one pathogenetic mechanism for chronic pancreatitis.

As emphasised in a recent review, a combina- tion of the different postulated pathogenetic mechanisms - primarily 'toxic', 'protein-plug', and 'necrosis-fibrosis' hypothesis - may be active in chronic pancreatitis. ${ }^{32}$

The authors are indebted to Professor T Gasser and Dr U Helfenstein for expert statistical advice. They express their thanks to C Elsener, G Hoegger, $M$ Sulser, and A Sixt for skillful technical assistance and to Dr A U Freiburghaus for the careful review of the manuscript.

The work was supported by the EMDO-Foundation, Zurich, and in part by the Amelie-Waring-Foundation, Zurich, Switzerland.

Presented in part at the 5th Meeting of the International Presented in part at the Sth Meeting of the Inter
Association of Pancreatology in Athens, September 1992.

1 Comfort MW, Gambill EE, Baggenstoss AH. Chronic relapsing pancreatitis; a study of 29 cases without associated disease of the biliary or gastro-intestinal tract. Gastrodisease of the biliary or gastro-intest
enterology $1946 ; 6: 239-85$ and $376-408$.

2 Sarles H, Muratore R, Sarles JS, Gaini M, Camatte R, Pastor $\mathrm{J}$, et al. Etiology and pathology of chronic pancreatitis. Bibl Gastroenterol (S Karger, Basel/New York) 1965; 7: 75120

3 Howard JM, Ehrlich FW. The etiology of pancreatitis - a review of clinical experience. Ann Surg 1960; 152: 135-46.

4 Howard JM, Ehrlich EW. Gallstone pancreatitis: a clinical entity. Surgery 1962; 51: 177-84.

5 Marks IN, Bank S. The etiology, clinical features and diagnosis of pancreatitis in the South Western Cape. $S$ Afr Med $\mathcal{F}$ 1963; 37: 1039-53.

6 Gyr KE, Singer MV, Sarles H, eds. Pancreatitis - concepts and classification. Amsterdam: Excerpta Medica, 1984: XXIXXVIII.

7 Sarles H, Adler G, Dani R, et al. Classifications of pancreatitis and definition of pancreatic diseases. Digestion 1989; 43: and de $234-6$.

8 Ammann RW, Akovbiantz A, Largiadèr F. Schueler G. Course and outcome of chronic pancreatitis. Longitudinal study of a mixed medical-surgical series of 245 patients. study of a mixed medical-surgical

9 Gullo L, Priori P, Labo G. Natural history of acute pancreatitis and its relationship to chronic pancreatitis. In: Banks PA, Porro GB, eds. Acute pancreatitis. Milan: Masson Italia Editori, 1984: 87-93. 
10 Strum WB, Spiro HM. Chronic pancreatitis. Ann Intern Med 1971; 74: 264-77.

11 Pitchumoni CS, Glasser M, Saran RM, Panchacharam P, Thelmo W. Pancreatic fibrosis in chronic alcoholics and non-alcoholics without clinical pancreatitis. Am $\mathcal{F}$
Gastroenterol 1984; 79: 382-8.

12 Ammann RW, Buehler H, Bruehlmann W, Kehl O, Muench $R$, Stamm B. Acute (non progressive) alcoholic pancreatitis: alcoholic pancreatitis. Pancreas 1986; 1: 195-203.

13 Malagelada JF. The pathophysiology of alcoholic pancreatitis. Pancreas 1986; 1: 270-8.

14 Klöppel G, Maillet B. The morphological basis for the evolution of acute pancreatitis into chronic pancreatitis.
Virchows Archiv A Pathol Anat 1992; 420: $1-4$.

15 Bank S, Greenberg R. Value of assessing 'risk factors' in acute pancreatitis. In: Burns GP, Bank S, eds. Disorders of the pancreas. New York: McGraw-Hill, 1992: 27-51

16 Dürr GHK. Acute pancreatitis. In: Howat HT, Sarles H, eds. The exocrine pancreas. Philadelphia: Saunders, 1979: 352401.

17 Seligson U, Cho-J-W, Ihse I, Lundh G. Clinical course and autopsy findings in acute and chronic pancreatitis. Acta Chir Scand 1982; 148: 269-74.

18 Mitchell CJ, Playforth MJ, Kellegher J, McMahon MJ. Functional recovery of the exocrine pancreas after acute pancreatitis. Scand $\mathcal{f}$ Gastroenterol 1983; 18: 15-8.

19 Angelini G, Pederzoli P, Caliari S, Fratton S, Brocco G, Marzoli G, et al. Long-term outcome of acute necrohemorMarzoli G, et al. Long-term outcome of acute necrohemorrhagic

20 Büchler M, Hauke A, Malfertheimer P. Follow-up after acute pancreatitis: morphology and function. In: Beger $\mathrm{HB}$, Büchler M, eds. Acute pancreatitis. Springer: Heidelberg, 1987: 367-74.

21 Martin E, Pederzoli P, Marzoli GP. Short- and long-term results after necrotizing pancreatitis. In: Beger $\mathrm{HB}$, Büchler M, eds. Acute pancreatitis. Springer: Heidelberg, 1987: $375-6$

22 Gullo L, Barbara L, Labo G. Effect of cessation of alcohol use on the course of pancreatic dysfunction in alcoholic pancreatitis. Gastroenterology 1988; 95: 1063-8.

23 Warshaw AL. Conservation of pancreatic tissue by combined gastric, biliary and pancreatic duct drainage for pain from chronic pancreatitis. Am F Surg 1985; 149: 563-8.

24 Mercadier M. Clot JP, Coquillaud PP. A propos d'une statistique homogène de plus de 100 cas de collections enkystées d'origine pancréatique. Ann Chir 1967; 21: 645 59.

25 Frey Ch F. Pancreatic pseudocysts - operative strategy. Ann Surg 1978; 188: 652-62.

26 Staub JL, Le Genissel H, Sarles H. Etudes de la sémiologie et des résultats du traitement chirurgical de 103 cas de pancréatite chronique compliqués de kystes ou de pseudokystes. Gastroenterol Clin Biol 1981; 5: 433-9.

27 Traverso LW, Tomkins RK, Urrea PT, Longmire WP Surgical treatment of chronic pancreatitis. Twenty-two year's experience. Ann Surg 1979; 190: 312-7.

28 Barthet M, Bugallo M, Moreira LS, Bastid Ch, Sastre B, Sahe $\mathrm{J}$. Management of cysts and pseudocysts complicating chronic pancreatitis. Gastroenterol Clin Biol 1993; 17:270-6.

29 Sarles H, Camarena-Trabous J, Gomez-Santana C, Choux R, Iovanna $J$. Acute pancreatitis is not a cause of chronic pancreatitis in the absence of residual duct strictures. pancreatitis in the abse

30 Laugier R, Camatte R, Sarles H. Chronic obstructive pancreatitis after healing of a necrotic pseudocyst. $A m \mathcal{F}$ Surg 1983; 146: 551-7.

31 Renner IG, Savage WT, Pantoja JL, Renner VJ. Death due to acute pancreatitis. Dig Dis Sci 1985; 30: 1005-18.

32 DiMagno EP, Holtmann G. Chronic pancreatitis. Curren opinion in gastroenterology 1992; 8: 824-9. 